\title{
Energy-Based Economic Development
}

Sanya Carley ${ }^{a,}$, , Sara Lawrence ${ }^{\mathrm{b}}$, Adrienne Brown ${ }^{\mathrm{b}}$, Andrew Nourafshan ${ }^{\mathrm{c}}$, Elinor Benami $^{\mathrm{d}}$

${ }^{a}$ School of Public and Environmental Affairs, Indiana University, 1315 East Tenth St., Bloomington, IN 47405, USA

${ }^{\mathrm{b}}$ RTI International, 3040 Cornwallis Rd., P.O. Box 12194, Research Triangle Park, NC 27709, USA

${ }^{\mathrm{c}}$ Nicholas School of the Environment, Duke University, P.O. Box 90328, Durham, NC 27708, USA

${ }^{\mathrm{d}}$ Department of Economics, University of North Carolina at Chapel Hill, CB 3305, Chapel Hill, NC, 27599, USA

* Corresponding author: sanya.carley@gmail.com; 919-265-4651 


\section{TABLE OF CONTENTS}

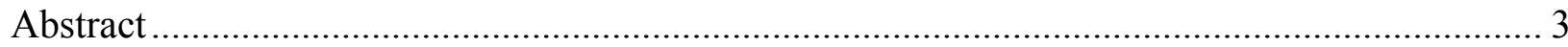

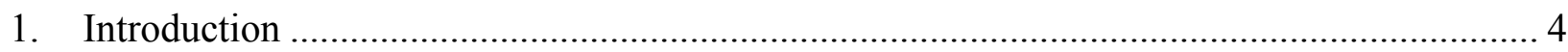

2. Economic Development and Energy Policy \& Planning: Evolution of the Fields.................... 6

2.1 The Field of Economic Development …………....................................................... 6

2.2 The Field of Energy Policy and Planning ……………................................................ 11

3. Convergence of the Fields: Funding and Activities .......................................................... 15

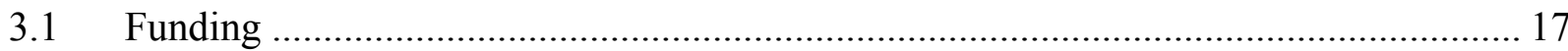

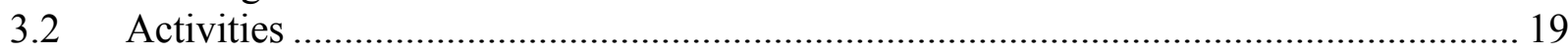

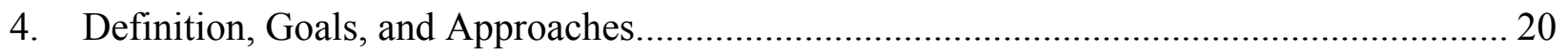

4.1 Definition of Energy-Based Economic Development................................................... 20

4.2 Goals of Energy-Based Economic Development.......................................................... 23

4.3 Approaches to Energy-Based Economic Development ................................................. 24

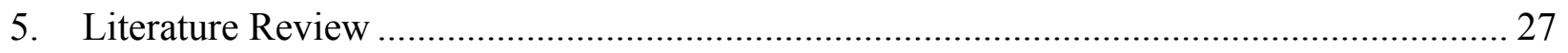

5.1 Needs for Energy-Based Economic Development..................................................... 27

5.2 Impacts and Benefits of Energy-Based Economic Development ……………….......... 28

5.3 Evaluation Methods............................................................................................... 36

5.4 The Need for a Comprehensive Approach to Energy-Based Economic Development . 37

5.5 Obstacles to Success in Energy-Based Economic Development ..................................... 39

6. Conclusions and Suggestions for Next Steps ………………………................................. 41

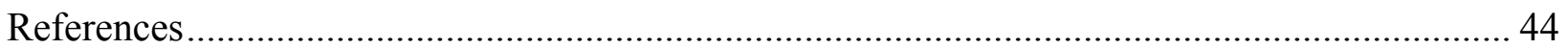

\section{LIST OF TABLES}

Table 1. Measuring Energy-Based Job Creation ...................................................................... 


\section{ABSTRACT}

The fields of economic development and energy policy and planning have converged in recent years to form an emerging discipline, which we term "energy-based economic development" (EBED). Despite the significant amount of stimulus funds, as well as state and local funding, that are being allocated to EBED initiatives in the United States, the emerging discipline has received scant attention in the energy, policy, and development literature. The link between energy and economic development in the literature is still theoretical, mostly focused on the need for and the potential benefits of EBED, and rarely applied. Furthermore, funding for EBED has outpaced understanding of the discipline, development of rigorous technical approaches, and meaningful ways to measure impact. Such information would not only help practitioners and policymakers more thoroughly understand the confines of the discipline and shape goals and approaches accordingly, but it would also help researchers identify, track, and evaluate a variety of activities in the field. With national and international attention focused on the convergence of these fields, researchers and practitioners have a rare opportunity to develop and implement the tools necessary to evaluate and communicate the potentially broader impacts that EBED may hold for society. If ways to leverage and sustain the injection of funds in this discipline are not identified, the opportunity may end before we can achieve either energy policy or economic development goals. In an attempt to respond to this need, this analysis explores the connection between energy and economic development, beginning with a review of the trends in each field and the goals that each seeks to achieve. On the basis of this information, we define the discipline of EBED, review the existing literature on it, and offer insights and perspectives on its emergence.

Keywords: energy policy, energy planning, economic development, stimulus funding 


\section{INTRODUCTION}

The American Recovery and Reinvestment Act of 2009 devoted over $\$ 50$ million to energy technology innovation, green jobs, and low-income energy efficiency assistance programs [1]. These efforts mark the convergence of two disciplines-energy policy and planning and economic development — and the expansion of a new field of practice and research, which we term "energy-based economic development" (EBED). EBED includes efforts that integrate both economic development and energy planning approaches.

Despite the indications that EBED is an important and growing discipline, the field is not yet well defined. A review of the literature reveals several unanswered questions about the theory and practice of EBED. For instance, what is it? What is our current state of understanding about it? Which approaches can government and community leaders take to incorporate EBED in their activities and initiatives? How do we measure the impact of these approaches?

The present analysis seeks to answer these questions and define the emerging field of EBED. Additionally, we clarify the subcomponents of EBED to minimize the use of vague or ambiguous descriptors prominent in current policy discussions. For example, the term "green" can be perceived and interpreted from both very broad and very narrow perspectives. "Green" can be a catchall phrase for any policy or initiative related to energy and the environment. Conversely, it can also convey a specific agenda, such as targeted measures to promote specific uses of renewable energy. "Energy" can also be an ambiguous term; to ensure clarity, for the purposes of this paper, all references to energy as it pertains to EBED will mean energy that is advanced, efficient, or clean.

- Advanced refers to technological innovation in either conventional or alternative sources of energy. 
- Efficiency is the amount of energy input divided by energy output. Greater efficiency means that less primary energy is required for the same amount of output energy.

- Clean refers to energy that is low carbon—or, in some cases, no carbon—and also improves the environmental footprint vis-à-vis conventional energy sources.

This is in keeping with the definitions that have been provided by Gallagher and her colleagues [2] for the field of energy technology innovation. Any mention of energy that does not follow this definition will be otherwise labeled.

Our analysis, which is primarily exploratory in nature, is based on extensive literature reviews and informal discussions and interviews with practitioners in the field. Although the field of EBED is not constrained to U.S. borders, for the sake of brevity this discussion is focused on U.S. trends. However, when applicable, we extend our discussion to include a consideration of the international context.

The value of performing this type of exploratory exercise — an attempt to document and discuss trends in an evolving field — cannot be understated. As established in the literature and discussed in subsequent sections of this paper, the field of EBED offers significant policy and planning opportunities to achieve simultaneous goals in the fields of economic development and energy. Past experiences with efforts in this field, however, are limited, so we have few lessons from which to draw. The policy "window" [3] or opportunity may be short-lived if we do not know how to implement EBED projects, identify the practices of greatest effectiveness and efficiency in different contexts, or evaluate these efforts. There is significant indication that the need for EBED will continue for decades, yet if we do not effectively maximize current opportunities, policymakers or their constituents may reject the field before EBED progress is effectively evaluated and becomes self-perpetuating. 
The next section offers a discussion of how the practices and objectives of energy planning and economic development have evolved through the years and become more coordinated with and complementary to each other. In section 3, we provide a working definition of EBED and review the goals and approaches that shape its practice. We review EBED funding trends in section 4 and the EBED literature in section 5. We conclude in section 6 with a discussion of avenues of further EBED inquiry.

\section{ECONOMIC DEVELOPMENT AND ENERGY POLICY \& PLANNING:}

\section{EVOLUTION OF THE FIELDS}

\subsection{The Field of Economic Development}

Economic development is a process of creating wealth for regions-nations or subnational regions such as states and counties - and improving the economic opportunities for the people that live and work within them. Desired results from this process include improved standards of living and reduced levels of poverty. Malizia [4] offers a broad but succinct definition of economic development:

The ongoing process of creating wealth in which producers deploy scarce human, financial, capital, physical and natural resources to produce goods and services that consumers want and are willing to pay for. The economic developer's role is to participate in the process of national wealth creation for the benefit of local consumers and producers by facilitating either the expansion of job opportunities and tax base or the efficient redeployment of local resources (pp. 83-84).

This definition underscores the importance of wealth creation and the role of the developer in facilitating it. Bolton [5] defines economic development policies as those that assist places and people that are economically distressed where policy intervention can increase 
prosperity. Eisinger, (p. 6) [6] extends this to specify that economic development has as its ultimate intent to "enhance the collective well-being" of communities.

The practice of economic development has evolved significantly over time. Although scholars offer a variety of interpretations as to how the field has progressed, ${ }^{1}$ we focus here on Eisinger's [6] depiction, in which the maturation of the economic development practice is marked by a shift from supply-side to demand-side approaches among states. Eisinger contends that state and local ${ }^{2}$ economic development practices, as they first emerged in the late 1800 s and continued through the mid-1900s, emphasized primarily supply-side strategies. During this time, practitioners sought to recruit industry and business to their regions to create jobs and increase wealth. Supply-side strategies are marked by competitive efforts with other states to capture mobile capital and to locate (or "supply") this capital in the economic developer's home state or locality. Initiatives to relocate or retain capital are targeted mostly at the firm level and typically

${ }^{1}$ For instance, Bradshaw and Blakely [7] Bradshaw TK, Blakely EJ. What Are 'Third Wave' State Economic Development Efforts? From Incentives to Industrial Policy. Economic Development Quarterly. 1999;13:229-44.) characterize the progress of economic development practice as taking place in three "waves." The first was marked by industrial attraction and characterized by programs to attract firms to relocate from the North to growing areas, such as the Southwest and South. In the 1980s the second-wave strategies emerged, in which economic development efforts targeted the retention and expansion of firms with indirect firm-level assistance. These practices evolved into third-wave strategies, which focused economic development efforts on growthbased strategies, as opposed to firm-based assistance.

2 Economic development in the United States is performed primarily at the subnational, or state and local, level, with a relatively limited federal role in economic development activities. The federal government mostly sets rules and regulations and funnels federal resources for economic development to states. As such, this paper focuses on the role of integrating energy development approaches at subnational levels. 
come in the form of low taxes on capital and labor or other government subsidies to reduce a firm's production costs. In these approaches, the government tends to follow the lead of private sector decision-makers about which kinds of products and businesses to target and which investments to make. (See Eisinger [6], p. 12, for more specifics comparing supply- and demandside approaches in economic development practice.)

Beginning around the mid-twentieth century, state and regional leaders shifted economic development efforts toward approaches that sought to increase entrepreneurial activity and generate global demand for locally made products and services (thus, "demand-side" approaches). These strategies are marked by support for entrepreneurship, innovation, and small business development and expansion. They seek to generate new capital through business creation and development by leveraging local assets and resources. Demand-side strategies also require active government involvement in market creation and development and make government responsible for guiding industries in directions that may be otherwise overlooked or underemphasized. This shift in focus from supply-side to demand-side strategies coincided with a variety of other economic transitions in the United States, including a change in the demographics of population centers, as populations moved from the North to the South and West; a devolution of economic development funding from the federal level to state governments; the globalization of economies; and the coinciding shifts in workforce requirements from manufacturing skills to technology-related skills and knowledge. The concurrence of these events raised interstate competition, which forced economic developers to experiment and broaden their approaches and forced states to seek greater income from state and local taxes for economic development purposes (Eisinger [6], pp. 10-11). 
This shift from pursuit of mobile capital to cultivation of local economic assets significantly shaped the evolution of modern economic development practices. A greater emphasis on demand-side approaches has led to a stronger and more dynamic relationship between the private and public sectors and encouraged governments to play a greater role in investment decision-making. Governments must therefore be more informed, proactive, and strategic. In general, public-private partnerships between government, businesses, and communities have grown in strength and prevalence [8]. Other trends marking modern economic development practice include the following.

- The field has replaced efforts focused on capital accumulation —including labor and land assets - with efforts focused on innovation and invention [8-13].

- Policymakers have improved the functionality and flexibility of tax subsidies and incentives that aim to attract and retain industry. They have also come to emphasize transparency and accountability in the design and implementation of these policy tools.

- Economic development strategies have shifted from a focus on agriculture and basic manufacturing to a focus on technology and advanced manufacturing. These strategies seek to establish a competitive advantage in the global marketplace.

- Guided by global competitiveness objectives, economic development efforts have shifted toward industrial development, organizational partnerships, and provision of value-added products and services that aim to enhance performance efficiency, improve the effectiveness of leadership, and develop technology.

- Cultivating and managing knowledge assets has evolved as an important component of innovation, entrepreneurship, and workforce development [8]. 
- The elevated importance of entrepreneurship and technological development has facilitated a greater role for higher education in economic development practice.

- In keeping with the trends outlined above, the field has expanded its notion of economic drivers to include venture capital and other equity capital markets; workforce and talent development and attraction; and university intellectual property and technology infrastructure including business incubators, science research parks, and sophisticated communication networks [14].

In the last quarter-century, the concepts of sustainability and the "triple bottom line" have also emerged in the economic development discourse and are gradually being incorporated into some practice [8]. At first, sustainability—and, more specifically, the environmental side of sustainability ${ }^{3}$-remained tangential to economic development research and practice because it was not deemed a significant driver of industrial recruitment, retention, innovation, or entrepreneurship. Over time, however, globalization trends have made sustainability a more important component of overall development, as explained by Stimson and his colleagues [8]:

Globalization is bringing about major changes to the flow of information and to governance systems, and the paradigm of sustainable development — the integrating of concerns for economic vitality, social equity and cohesion, and ecologically sustainable development—increasingly is being adopted as an underlying principle of regional development strategies and for planning practices.

This trend contrasts with the prior view of energy in economic development, where energy was typically considered only as one of many costs of production for companies making

\footnotetext{
${ }^{3}$ Definitions of sustainability also include social and economic dimensions.
} 
investment relocation decisions and energy-related expenditures were relatively minor compared with other inputs, such as physical infrastructure or labor. Recent increases in and volatility of energy costs, unpredictability of energy markets, desires for greater energy self-reliance, and emphasis on sustainability practices have pushed energy into more prominence in economic development.

\subsection{The Field of Energy Policy and Planning}

The field of energy policy and planning includes actions taken by government, not-forprofit, or private organizations to plan energy resource use, develop policy instruments to shape direct energy (i.e., heat) or secondary energy (i.e., electricity) production and consumption, and regulate oversight over energy resources. These efforts include issues spanning the full fuel cycle of all energy resources, including location, extraction, transportation, refinement, processing, combustion or other use, and waste disposal as well as supply-side, demand-side, ${ }^{4}$ and information or knowledge energy resource management.

An abbreviated history of the energy policy and planning field over the past half century is as follows. Policies stemming from the New Deal provided the first, albeit very minimal, glimpse of energy policy and planning with the citing and building of new centralized power plants to meet rapidly increasing electricity demands. In the 1970s—when the United States confronted the oil shocks of 1973 and 1979, a nuclear mishap at Three Mile Island, and a growing consumer awareness of the deleterious effects of energy-related pollution—energy

\footnotetext{
${ }^{4}$ In contrast with the economic development concepts of "supply-side" and "demand-side" introduced in the previous section, "supply-side" in the energy context refers to the resources and technologies used to produce energy. "Demand-side" refers to factors and approaches related to energy consumption, e.g., energy efficiency and load control.
} 
policy efforts expanded. ${ }^{5}$ Energy planning became more popular during the 1980 s, when many state utility commissions mandated that utilities create integrated resource planning programs to track resource use and facilitate demand-side management efforts.

After this flurry of activity, the focus on energy policy and planning faded as oil costs normalized and, with no perception of an imminent environmental threat, environmental concerns dissipated. This was the prevailing attitude until the mid-1990s, when the international community began to process issues related to climate change, including the potential economic burden associated with both the mitigation of and adaptation to climate change. As the 1990s progressed and a new century began, two additional factors raised the status of energy reform on many policymakers' agendas: energy fuel price volatility and a growing concern that dependence on foreign fuels was an economic security threat.

The coalescence of these three issues — climate change, energy prices, and energy security 6 - reaffirmed the significant connection, if not reciprocal relationship, between energy development and economic growth. ${ }^{7}$ With minimal national leadership on energy and climate

5 New federal legislation in the 1970s included the National Environmental Policy Act (NEPA), the 1977 Clean Air Act, and the National Energy Act of 1978, which included the Public Utility Regulatory Policies Act (PURPA). The Carter administration also created the Department of Energy in the late 1970s.

6 One could argue that other factors were at play and also significantly shaped the direction of U.S. energy policy and planning during this period. For instance, electricity reliability concerns, as made most evident by California's 2000 and 2001 blackouts, also contributed to energy's growth as a policy priority.

${ }^{7}$ It is important to note, however, that the connection between energy and economic development was established more concretely in the international development realm over two decades ago. The importance of energy access as it relates to the primary needs of all individuals, economic well-being, and personal standards of living, has been established firmly in the literature and has gained verification by the development community [15] UNDP. 
policy, ${ }^{8}$ many state and local entities — both governmental and nongovernmental—-stepped into leadership roles by initiating efforts to increase diversification of energy sources, increase energy self-sufficiency, or both. Instead of focusing on carbon mitigation policy, many of these energy policy and planning reforms pursued revamped initiatives on economic development grounds [18-19], in pursuit of "home-grown" energy [18] or as a means of diversification of state or regional economies to improve competitiveness. One reason for this approach is that, although alternative energy industries are immature compared with conventional energy industries, they represent opportunities for substantial investment and growth. Thus, many state and local energy strategies are attempts to "stay ahead of the curve," gain an early market share, and profit from future energy developments. Another explanation, however, is that framing energy reform on economic development grounds makes energy policy inherently less partisan and more politically feasible — rarely do policymakers contend that economic development is an ill-advised objective, but energy for the sake of climate change mitigation or reduced dependence on foreign fossil fuels is not as universally accepted. Furthermore, efforts framed in economic development discourse obviate the need for policymakers and their constituents to agree on which of the many energy or climate-change challenges are most threatening; such framing instead provides a

Energizing the millenium development goals: a guide to energy's role in reducing poverty. United Nations Development Pro-gramme; 2005, [16] Nissing C, Blottnitz H. Renewable energy for sustainable urban development: Redefining the concept of energisation. Energy Policy. 2010;38:2179-87, [17] World Bank. Rural Energy and Development: Improving Energy Supplies for Two Billion People. Washington, DC: World Bank; 1996.

${ }^{8}$ The national government was involved in energy policy efforts during this time as well, but these effortsincluding the Energy Policy Act of 1992, Order 888, Order 889, and Order 2000-were mostly focused on increasing competition in the electricity sector. 
platform for energy reform that has the potential to address multiple issues simultaneously, but with the least political tension.

As state and local energy policy and planning efforts have gained momentum over the past 15 years, the efforts have become increasingly focused on energy technology innovation, which is defined as

The set of processes by which improvements in energy technology, which may take the form of refinements of previously existing technologies or their replacement by substantially different ones, are conceived; studied; built, demonstrated, and refined in environments from the laboratory to the commercial marketplace; and propagated into widespread use [2] (p. 195).

In other words, energy technology innovation focuses on innovative development and deployment of efficient, reliable, advanced, and low- to no-carbon energy technologies, including demand- and supply-side technologies. These technologies are intended to serve one of two roles: (1) as a replacement or enhancement to conventional sources of energy; or (2) to "leapfrog" or completely bypass technologies based on conventional sources in favor of more advanced technologies.

States and localities continue to play a leading role in shaping energy policy and planning, and they demonstrate the expanded role for government intervention and public policy efforts in energy markets. Policymakers in the energy technology innovation field use a variety of different policy instrument combinations that aim to provide incentives for the development and deployment of innovative energy technologies. Policy instruments tend to include flexible and market-based instruments, financial incentives (e.g., research and development grants, public benefit funds, tax incentives), or hybrids of different instruments that demonstrate elements of 
both command-and-control and market-based designs (e.g., the renewable portfolio standard). States, regions, or local governments tend to choose among a variety of instrument options and to specifically tailor the selected instruments to their local needs and circumstances. Policy efforts in this field also aim to establish functional and working relationships between public and private actors. Similar to the economic development discipline, states and localities have emerged as the laboratories for policy development and implementation in energy policy and planning.

\section{CONVERGENCE OF THE FIELDS: FUNDING AND ACTIVITIES}

As shown in the discussion of evolution of the two fields, economic development and energy policy and planning have begun to converge. Both theory and practice in economic development have come to emphasize local asset-based competitiveness, technology innovation, local or regional scale, and a growing significant role for public policy and public-private partnerships in shaping the development of economies. Similarly, the field of energy policy and planning has evolved to emphasize local resources, technology innovation, a mix of policy interventions mostly implemented at the subnational level, and functional public-private partnerships. It is now becoming common to find economic development initiatives that involve energy strategies, or energy policy and planning initiatives that involve economic development elements. The evolution and current trends in each field, as shown in Figure 1, demonstrate a support of development and progress in the other and, thus, a greater integration of the two movements. 
Figure 1. Parallel Evolution and Converging Goals of the Fields of Economic Development and Energy Policy and Planning

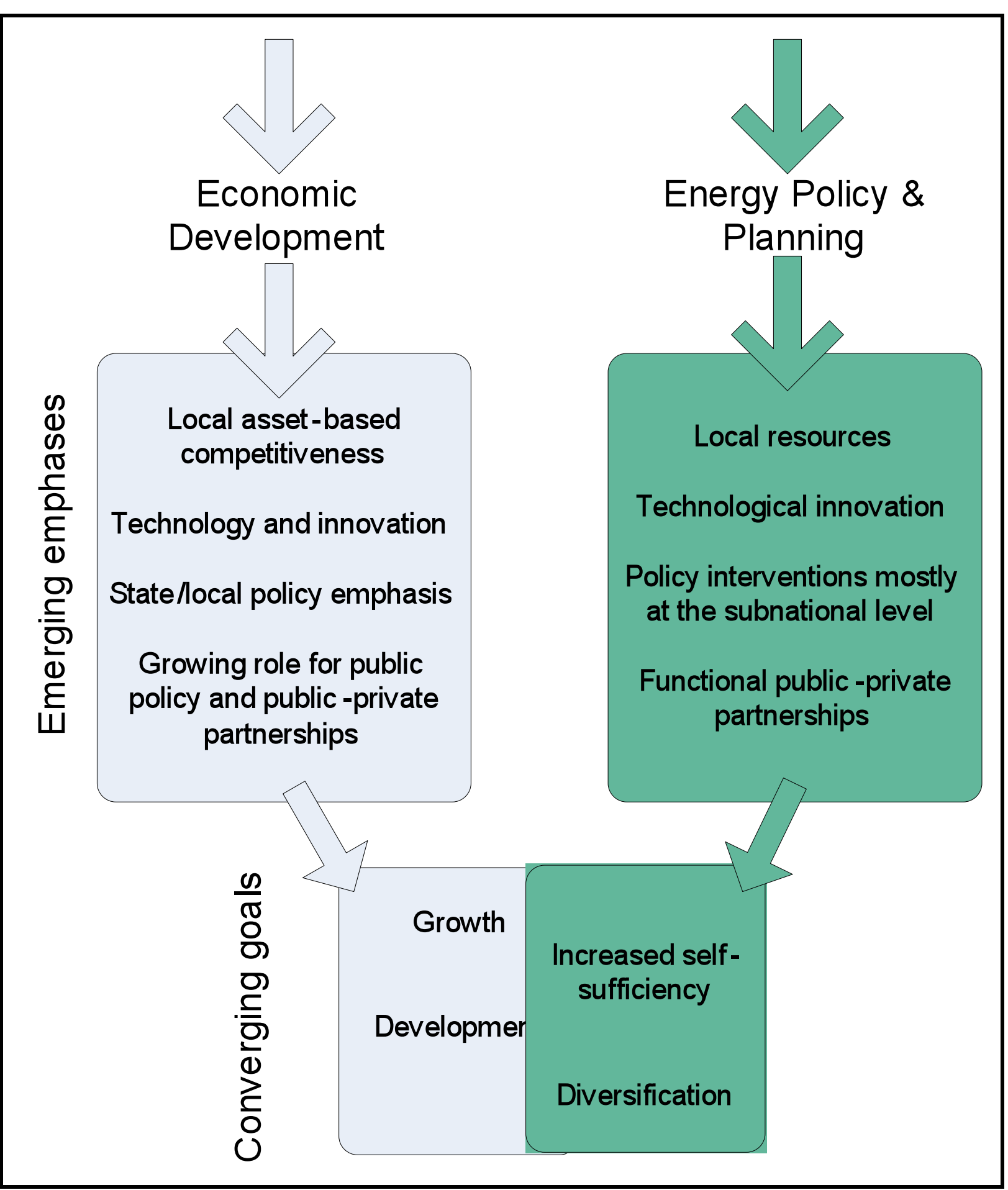


In addition to parallels in how the fields have emerged, the goals of each discipline frequently complement those of the other. Energy policy and planning seeks to improve energy self-sufficiency (which can result in the creation of businesses that are unlikely to relocate outside a given region) and increase energy diversification (which can result in the creation of new technologies, businesses, and jobs). Economic development initiatives may seek to catalyze growth through innovation, which can result in increases in energy efficiency or the creation of new technologies that diversify a given region's sources of direct or secondary energy.

\section{1 $\quad$ Funding}

Funding and investment at the intersection between economic development and energy policy and planning has also been on the rise over the last decade, further driving the convergence. According to the most recent United Nations Environment Programme's Sustainable Energy Finance Initiative (UNEP-SEFI) report, Global Trends in Sustainable Energy Investment 2009, global investment in sustainable energy companies or projects totaled over $\$ 155$ billion during 2007 and 2008, a tremendous amount of growth from approximately $\$ 22$ billion in $2002 .{ }^{9}$ Most of these funds were invested in renewable energy technology research and deployment, in such areas as biofuels, geothermal, wind, hydroelectric, solar, and marine energy. Although many sectors of the economy saw a decline in investment during the recent global economic recession, investment has continued to grow—if at a slower pace—-for alternative energy projects. Stimulus packages from various countries have allocated significant funds to energy projects. More specifically, national economic stimulus packages have earmarked roughly $\$ 180$ billion to $\$ 200$ billion for energy projects $[1,20]$, with the following countries

\footnotetext{
9 These estimates are extracted from the funding summaries most readily accessible via public-access Internet research.
} 
ranking high on the list for recovery plans incorporating energy supply and energy efficiency components.

- China: $\sim \$ 70$ billion for electricity grid upgrades and $\$ 12$ billion to energy conservation and environmental protection projects

- United States: $\sim \$ 68$ billion (described in further detail below)

- Japan: $\$ 11$ billion for energy efficiency

- South Korea: $\$ 8.5$ billion for energy efficiency projects

The American Recovery and Reinvestment Act (ARRA) of 2009 is the U.S. effort to create and retain jobs and stimulate the national economy. To achieve one of its secondary goals of jumpstarting the transformation of the nation's energy infrastructure through energy generation technologies, ARRA allocated billions of dollars in funding to energy provision and energy efficiency projects; workforce development and training; and research and development for alternative, advanced energy, and energy efficiency technologies.

As shown in Figure 2, ARRA also made $\$ 21$ billion available for tax incentives to alternative energy manufacturers and more than $\$ 30$ billion for direct spending [1]. 
Figure 2. Distribution of EBED-Related ARRA Direct Spending

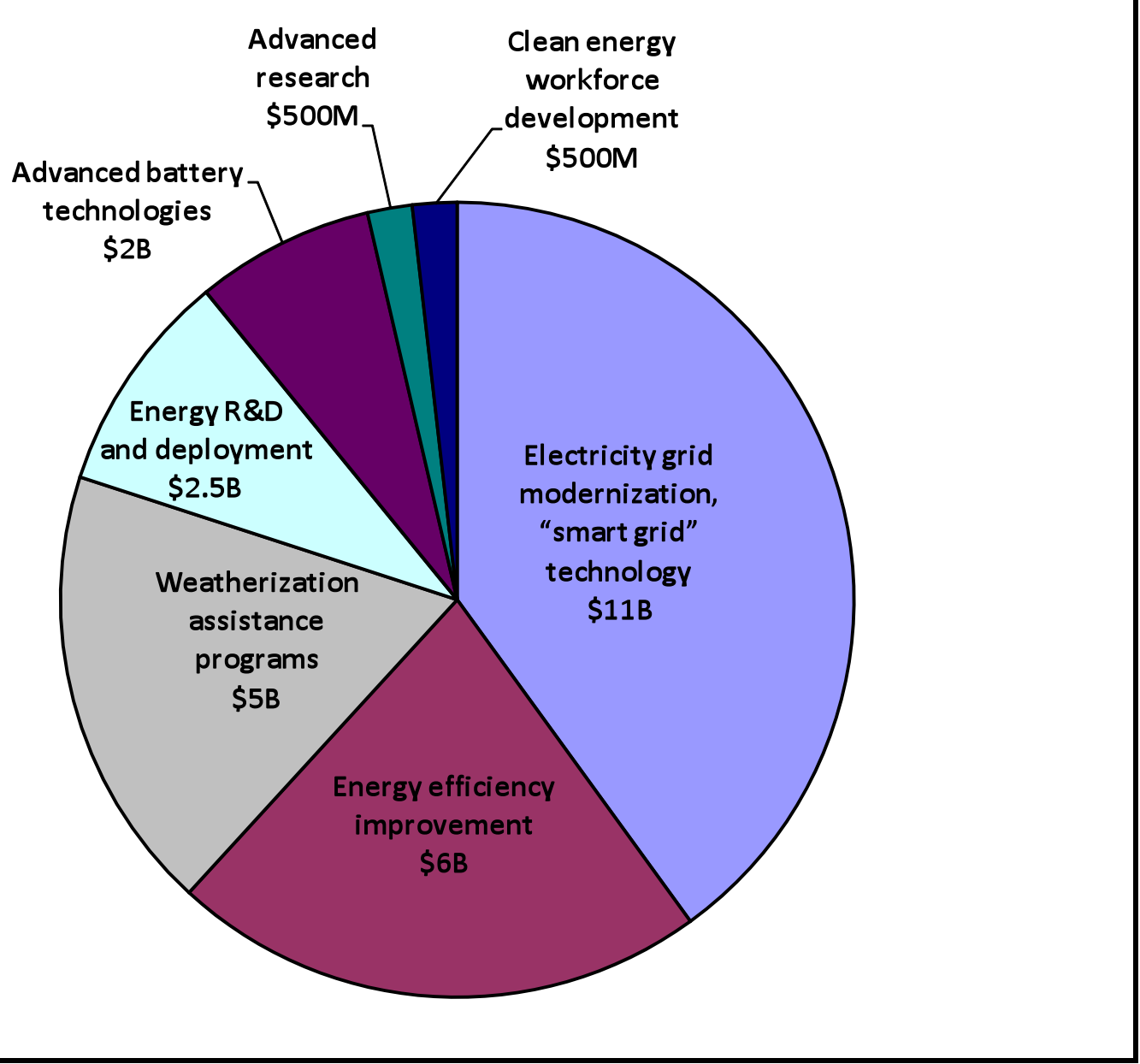

EBED, energy-based economic development; ARRA, American Recovery and Reinvestment Act; R\&D, research and development; \$M, millions of dollars; \$B, billions of dollars.

\subsection{Activities}

Figure 3, updated and adapted from Roberts [21], characterizes the relationships between a selection of activities typically undertaken within economic development and those undertaken as part of energy policy and planning. The overlap of these activities further underscores the notion of convergence of fields and indicates activities with the strongest connections. The activities listed in the figure are not all-encompassing, and there are subsets of important activities within each of these categories. However, Figure 3 is important because it does demonstrate the major activities within each practice and how they intersect. 
Figure 3. Intersection of Economic Development Activities with Energy Policy and Planning Activities

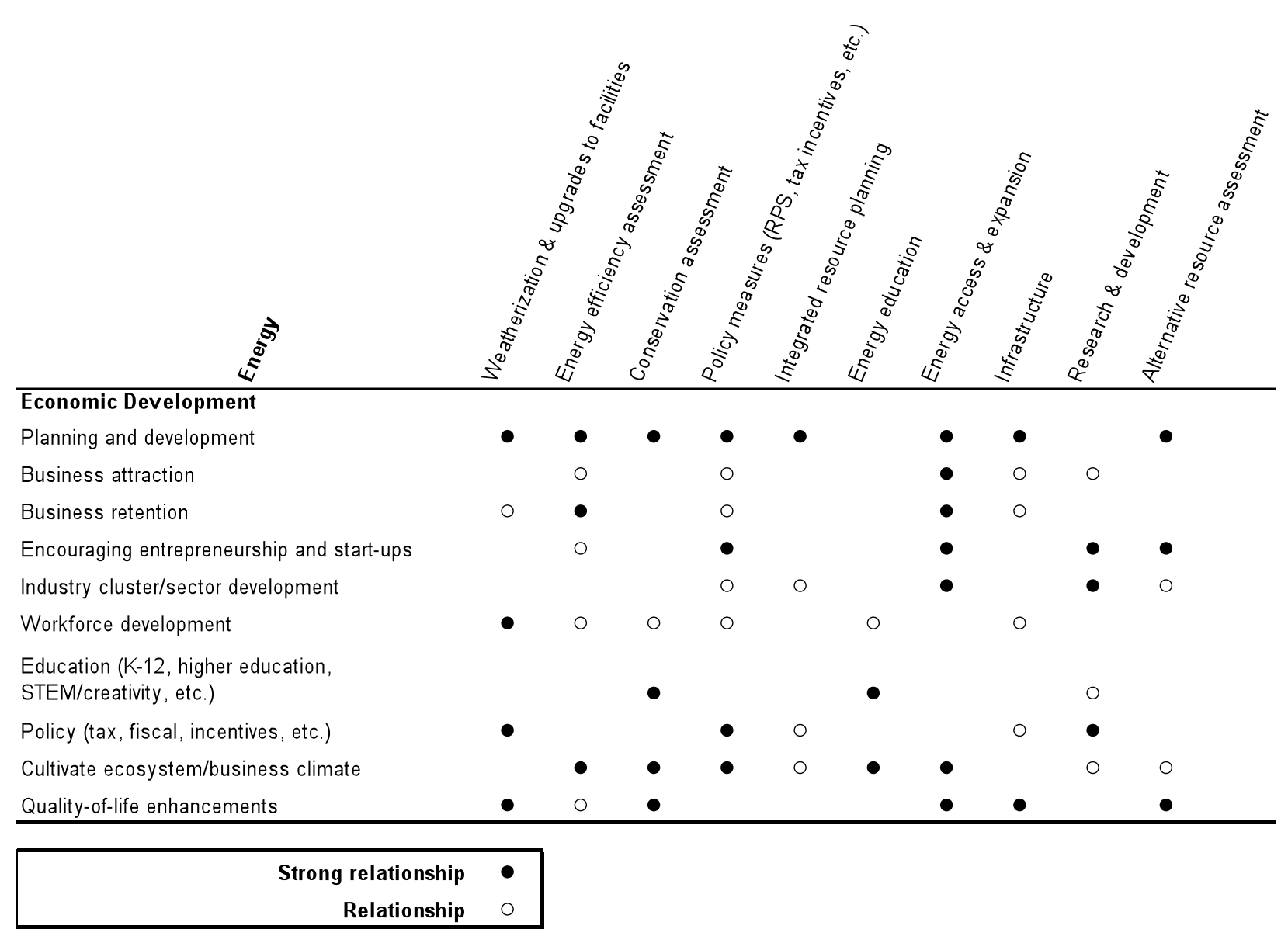

\section{DEFINITION, GOALS, AND APPROACHES}

\subsection{Definition of Energy-Based Economic Development}

Despite the demonstrated overlap in focus areas and convergence of goals across the two fields of economic development and energy policy and planning, a single, agreed-upon, widely used definition of the emerging field of EBED does not yet exist. In the United States, this lack of shared understanding, in combination with the sudden injection of stimulus funding for activities at the intersection of the two fields, has resulted in significant confusion. The use of "green" as a catch-all phrase for activities that involve energy or the environment is an example 
of this confusion. This confusion is harmful to the new field in a number of ways, including the following:

1. Attention has been focused predominantly on clarification of terminology and classification of activities, hindering the development of meaningful, comprehensive approaches that effectively incorporate the goals of both fields.

2. The absence of a definition and shared terminology has potentially resulted in the allocation of funds to projects that claim to meet both energy and economic development objectives but do not, thereby enervating the effectiveness of the allocated resources.

3. Inconsistent information and short funding horizons make it difficult to establish metrics and mechanisms for evaluation of activities, further hindering the development of the field and, more importantly, the identification of successful approaches and practices.

More clearly defining the field and the approaches within the field will help practitioners manage resources, implement projects, evaluate outcomes, and advance successful methods. To that end, we offer the following definition.

Energy-based economic development is a process by which economic developers; energy policymakers and planners; government officials; industry, utility, and business leaders; and other stakeholders in a given region strive to increase energy efficiency or diversify energy resources in ways that contribute to job creation, job retention, and regional wealth creation.

This definition is broad, but it is a marked contribution to the field for three important and distinct reasons: 
- It encompasses the array of benefits that can converge under the disciplines of energy policy and planning and economic development. For example, whereas the more narrow interpretations of ambiguous terminology such as "green" may not value technologies that improve the efficiency of oil and gas extraction, this definition recognizes that these processes do increase energy efficiency and perhaps retain jobs for a region.

- It holistically describes the convergence of energy policy and planning and economic development, allowing for a wide set of policies and practices directed at the goals of EBED (see section 4.2 below for a description of EBED goals). In short, the goals are increased energy efficiency, diversification of energy resources, job creation and retention, and regional wealth creation. This framework, more expansive than previous definitions, creates a greater opportunity to generate a host of EBED activities and initiatives.

- It allows for alignment between the goals and objectives of community stakeholders and energy policy and planning activities, which in turn grounds energy-related initiatives with a wider set of local champions. Before this convergence, energy policy and planning decisions were typically made by utility companies, regulators, and policymakers. Incorporating economic developers, community development practitioners, local officials, and others builds a more robust framework for crossfertilizing activities among different types of stakeholders. The result is the potential generation of more innovative, more prolific local and regional problem-solving of EBED issues. 


\subsection{Goals of Energy-Based Economic Development}

To expand on the goals set forth in the definition, and to demonstrate the potential range of EBED activities, we divide EBED goals into four, not mutually exclusive, categories.

Increasing energy self-sufficiency, the first goal, originates from the energy policy and planning field. The national focus on energy security - the notion that a dependence on energy sources that come from outside of a jurisdiction's borders poses a risk to the economic and personal security of that jurisdiction's inhabitants - has translated to similar focus on energy "independence" at a subnational level. At a national level, these potential risks are of particular importance when the energy resources are extracted from regions that are politically instable or that may be susceptible to natural or terroristic disasters [22]. As energy prices rise and regions must spend a greater share of their fiscal resources on imported energy resources, the perceived need to replace imported energy with home-grown energy continues to rise. At a subnational level, the focus is less on actual security and more on regional competitiveness, potential for job creation and retention, or the utilization of resources. This increased focus on local and regional resources aligns well with the push for increased use of alternative resources, because advanced, alternative energy tends to come from local or regional sources.

The second goal is energy diversification, which refers to the development and use of new or alternative resources or technologies that emit fewer greenhouse gases or other environmental pollutants and are more efficient. Energy diversification has the potential to increase energy reliability and provide enhanced energy security through reduced dependence on sources that exhibit volatility in fuel price.

The third and fourth EBED goals are economic growth and economic development. Economic growth refers to the creation of jobs or expansion of business activity, which increases 
personal and household incomes and, in turn, the local or state tax base and larger macroeconomic indicators such as gross domestic product and industry growth as defined though increased revenues. Economic development adds an element of qualitative improvement to the quantitative focus of growth. It may include catalyzing activity in new and emerging industry sectors to diversify the regional economy and better absorb regional economic shocks. Economic development also works to improve factors that contribute to a healthy economy, such as business climate, workforce, healthcare provision, education, and quality of life.

\subsection{Approaches to Energy-Based Economic Development}

Describing the four goals of EBED is important because it sets the stage for crafting meaningful approaches for implementation by practitioners in communities, states, regions, and countries. With this transition from goals to approach, it is useful to discuss process as an important factor in creating approaches for implementation. We introduce process through the lens of economic development planning because it is well established and encompasses a variety of issues. The planning process generally follows a path that includes the following elements: stakeholder engagement, identification of goals and objectives, assessment of assets and gaps that enable or constrain attainment of goals and objectives, comparison and selection of alternative interventions, implementation, and evaluation. Outcomes are measured against the goals and objectives initially established, with this feedback creating a circular process. The EBED process is similar, but diverges in several key ways:

- Utility operators and landowners or regulators of natural resources will be critical stakeholders. 
- The data and information gathered in the assessment phase will include additional indicators (e.g., energy capacity and demand forecasts, energy efficiency resource potential, renewable energy resources).

- The toolbox of potential interventions includes additional activities, as detailed below.

As is the case with standard economic development, identification of appropriate interventions will depend on regional context — the region's assets and gaps, goals and objectives. Following are illustrative EBED approaches.

- Regional economic development practice in the United States focuses heavily on specialization, that is, on competitiveness within a few industries in which a given region has some advantage or concentration. Given this context, many economic development interventions fall within the category of industry developmentpolicies and initiatives that aim to increase business activity (e.g., sales, revenues, jobs) within a certain industry sector or interrelated set of industries, generally to increase or diversify the tax base. These interventions may include targeted business recruitment, retention or expansion support of businesses in a target industry, policies that improve the business climate for a target industry, or initiatives that support the creation of new businesses within a target industry. Industry development in the EBED context might aim to increase regional economic activity within the wind power, hydropower, solar energy, biofuel, or geothermal energy industries.

- The creation and support of new businesses is a key driver of regional economies, with recent research showing that firms younger than 5 years account for nearly twothirds of job creation in the United States [23]. Entrepreneurship development 
policies and programs provide potential entrepreneurs with the capital and technical assistance they need to start and grow their businesses. As in industry development, an EBED entrepreneurship initiative might target potential entrepreneurs in the wind power, hydropower, solar energy, biofuel, or geothermal energy industries.

- New and existing businesses alike depend on innovation, especially in emerging and quickly evolving clean energy industries. To support these industries, regions need an effective and seamless infrastructure for the creation of new ideas and their transfer to market. EBED research and innovation support strategies strengthen, link, or create regional assets for knowledge creation and transfer to create, sustain, and grow energy businesses.

- All three of the preceding types of strategies — and regional competitiveness itselfdepend heavily on the availability of educated, skilled human capital. Workforce development, broadly, describes the public- and private-sector policies and programs that provide individuals with the means and opportunity to obtain employment and that provide companies the skilled employees they need to compete. As energy companies form and develop, they will increase demand for employees with skills and training in existing and new occupational categories. Meeting this need will require such varied activities as (1) enhancing the energy knowledge of workforce service providers and updating existing curricula to include alternative energy concepts and skills and (2) forging new partnerships between educational institutions and employers to design new curricula, certifications, and degrees.

- Energy self-sufficiency approaches include weatherization strategies; the development and deployment of energy efficiency technologies; the development and 
deployment of smart-grids; the use of distributed generation; improved manufacturing processes and product development; and development of energy technologies that employ local resources or other technologies that use local energy inputs.

- Diversification of energy resources includes the expansion of energy access and the development and deployment of advanced, efficient, and low- to no-carbon sources of energy.

\section{LITERATURE REVIEW}

Despite the nascence of the field, given the convergence described above and the funding allocated toward these activities, the sheer amount of recent discussion of EBED in both the peer-reviewed and other literature comes as no surprise. Supporting the discussion in the prior section, a review of these studies reveals that the link between energy and economic development is still primarily conceptual and theoretical, mostly focused on the need for and the potential benefits of EBED, and is only rarely applied.

The literature is divided into five categories: the need for and opportunities of EBED; the benefits of such efforts; methodological approaches to EBED assessments; calls for a comprehensive approach to EBED; and complications to success in this discipline.

\subsection{Needs for Energy-Based Economic Development}

A number have authors have cast the EBED process and a subset of it, "green" economic development approaches, as representing a clear opportunity to bring together two divergent fields and their respective stakeholders (examples include Blue-Green Alliance, Ong and Patraporn, and Toman and Jemelkova [24-26]). Those looking for a pathway by which new measures can be undertaken to improve the energy system have found themselves looking at economic development stakeholders as effective political allies. Concurrently, economic 
development professionals increasingly view the energy system as a source of potential economic opportunity.

The body of literature in this category is divided by which field it draws on more heavily: it either focuses on the potentially significant role of economic development to address the demand for decarbonized energy consumption and improved energy self-sufficiency; or it focuses on the role of energy-related industries, technologies, and processes to drive job creation and industry retention [27-28]. Those focused on the former see EBED as a means to take energy policy beyond its traditional environmental framework, moving beyond quotas, emissions limits, and pollution prices, toward a discussion about investment in infrastructure to promote robust economic development and improved standards of living [29].

\subsection{Impacts and Benefits of Energy-Based Economic Development}

The literature on the benefits of EBED focuses primarily on the potential for job creation associated with increased investment in energy supply and energy efficiency. In many cases, researchers [26-27, 29-30] contend that a large percentage of this employment is made up of jobs that are guaranteed to remain domestic (i.e., they are not at risk of being fulfilled by overseas labor), because the installation of energy systems involves site-specific installation and construction. Atkinson and others [31] have highlighted the need for the United States to significantly increase its investment in research and development, as part of a longer-term EBED strategy, to remain globally competitive.

Another common focus of the literature is the economic development potential of energy efficiency measures. In addition to energy efficiency's offering the opportunity for new job creation — because of an increase in construction and installation jobs—it also provides cost savings from unspent energy budgets that can be redirected toward other sources of economic 
activity [32-34]. Ultimately, a common conclusion of many works in this field is that the creation and adoption of low-carbon energy technologies aimed at energy generation and efficiency tend to create more jobs per unit of installed capacity than conventional approaches. Despite this commonality in the literature, comparing the various studies devoted to this topic is difficult because the key inputs used in these analyses are significantly inconsistent: the technologies examined, the regions studied, the types of employment effects (i.e., direct, indirect, and induced), and even the definition of what constitutes a "job" (full-time or part-time, temporary or long-term). Differences in these inputs and other assumptions have led to a wide variety of job growth estimates and multipliers for EBED and have contributed to the confusion discussed in the preceding sections. Moreover, significant methodological differences are found in the modeling efforts. Regardless of these inconsistencies, it is interesting to examine a selection of this research to get a stronger understanding of the literature on estimated benefits.

Table 1 outlines the key findings and important distinguishing characteristics of a number of prominent studies found in the literature. For additional discussion of the trends in the differences between the preponderance of "green job" studies, refer to Wei et al. [35]

As mentioned above, because of the wide variety of factors involved in these studies (methods, inputs, energy focus, and time frames, etc.), it is difficult to draw distinct conclusions from this table for the purposes of this paper. Instead, with a practitioner focus in mind, we aim to demonstrate how researchers are increasingly demonstrating job effects. Accordingly, this table is organized with a focus on jobs. Just under half of these studies report job figures as measured by unit of energy output. This seems to be particularly helpful for practitioners comparing job creation within the types of energy technologies deployed. For example, Sastresa 
et al. [36] show that solar thermal creates 43 jobs per megawatt (photovoltaic, or PV) and wind creates 0.86 jobs per megawatt in Aragon, Spain.

One can also estimate the total number of jobs that will result depending on which energy technologies or renewable energy standards are adopted. For example, the American Solar Energy Society estimates the number of jobs to be created in renewable energy and energy efficiency under basic, moderate, and advanced scenarios of industry growth.

Only one study [37] explicitly looked at the job loss and job creation aspect as an impact, demonstrating the importance of measuring the positive and negative effects of turbulence in regional economies. Other forms of describing impact, shown in the last two rows of the table, are multipliers and effects on gross domestic product.

A final important finding from this review is that the literature is composed almost entirely of modeling estimates performed before EBED implementation, rather than assessment of effects after implementation. Studies that were performed before EBED implementation are designated as "pre" in the table; studies that were performed after EBED implementation are designated as "post." These trends highlight the relative youth of the field and the dearth of practical experience for the literature to draw from, particularly in the United States.

Although most of the literature has focused on the positive effects associated with EBED, these studies are also accompanied by critics, who raise concerns about the methods of accounting for green jobs, the efficacy of using public funds for energy projects instead of for other capital-intensive efforts, and the possibility of energy expenses' crowding out other business investments. For further discussion of these critical points, as well as others, see recent work by Calzada Alvarez, Center for Energy Economics, and Morriss [37-39]. 